Research Paper

\title{
Fibrinogen and C-reactive protein score is a prognostic index for patients with hepatocellular carcinoma undergoing curative resection: a prognostic nomogram study
}

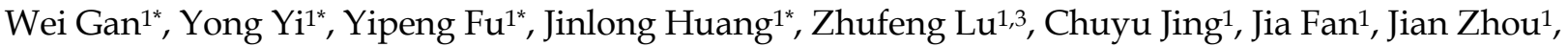 \\ Shuangjian Qiu1,2匹 \\ 1. Liver Cancer Institute, Zhongshan Hospital and Shanghai Medical School, Fudan University, Key Laboratory for Carcinogenesis \& Cancer Invasion, The \\ Chinese Ministry of Education, Shanghai, China. \\ 2. Biomedical Research Center, Zhongshan Hospital, Fudan University, Shanghai, China. \\ 3. Department of Anesthesiology, Zhongshan Hospital, Fudan University, Shanghai, China. \\ *These authors are co-first authors. \\ $\square$ Corresponding author: Shuangjian Qiu, MD. PhD. Liver Cancer Institute and Biomedical Research Center, Zhongshan Hospital, Fudan University, 180 \\ Fenglin Road, Shanghai 200032, People's Republic of China. Telephone: 86-21-64037181; e-mail: qiu.shuangjian@zs-hospital.sh.cn \\ ( $)$ Ivyspring International Publisher. This is an open access article distributed under the terms of the Creative Commons Attribution (CC BY-NC) license \\ (https://creativecommons.org/licenses/by-nc/4.0/). See http://ivyspring.com/terms for full terms and conditions.
}

Received: 2017.08.06; Accepted: 2017.10.19; Published: 2018.01.01

\begin{abstract}
Background: While curative resection is the established strategy for Hepatocellular carcinoma (HCC) patients, the prognosis still remains poor, and the efficiency of existing prediction models is unsatisfactory. Therefore, we aimed to develop a credible and easy-to-use prognostic index for patients with $\mathrm{HCC}$ undergoing curative therapy.

Methods: A total of 768 patients with HCC, who underwent curative resection from December 2010 to June 2012 in Zhongshan Hospital, were divided into a training cohort with 616 patients and a validating cohort of 152 patients at a ratio of 4 to 1 by random allocation. Then, a retrospective cohort study was conducted to identify effective prognostic indexes.

Results: FC-score, which incorporates fibrinogen and C-reactive protein, was established. In the multivariate analysis for OS and RFS, FC-score has shown to be a significant independent prognostic index in both the training cohort and validation cohort. Furthermore, the C-index of the FC-score for OS and RFS were 0.698 and 0.594 respectively, which were superior to other inflammation systems such as IBI, IBS, and GPS. Then, we developed a novel nomogram, which integrated FC-score into the conventional BCLC staging system. This new nomogram gave rise to a new C-index of 0.746 ( $95 \% \mathrm{Cl}$ : $0.743-0.749)$ for OS, and 0.654 ( $95 \% \mathrm{Cl}: 0.652-0.656)$ for RFS. The calibration curve and decision curve analysis indicated that our nomogram was highly consistent between predicted and actual observations.

Conclusions: FC-score represents a novel, convenient, reliable, and accurate prognostic predictor for both OS and RFS in HCC patients undergoing curative therapy.
\end{abstract}

Key words: Hepatocellular carcinoma; FC-score; nomogram; prognostic; fibrinogen

\section{Introduction}

Hepatocellular carcinoma (HCC) is a globally prevalent malignant tumor that represents the fifth most common newly-diagnosed cancer, and the second most common cause of mortality, and HCC-related morbidity is rising rapidly [1-3].
Although, radical excision is the established therapeutic strategy for HCC, the rates of both recurrence and metastasis after resection remain high, and the prognosis remains poor. To the best of our knowledge, the prognosis of HCC patients after 
curative resection depends not only on the clinical stage of the tumor at operation, but also on the degree to which liver function is affected $[4,5]$. These factors make it very difficult to predict the prognosis of HCC patients.

The Barcelona Clinic Liver Cancer (BCLC) staging system is the most widely used and complete evaluation system for therapeutic allocation, as well as prognostic stratification [6, 7]. However, evidence has shown that the BCLC is relatively limited to the advanced stages of patients with HCC, while the Cancer Liver Italian Program (CLIP) was validated to be more appropriate to patients with early to advanced HCC [8]. A research study carried out by Camma et al. reported that the CLIP system was more suitable for predicting prognosis in advanced untreated patients, while the BCLC outperformed the CLIP system for predictions in early stage patients under treatment [9]. Another study suggested that there was no widely used prognostic scoring systems for HCC because of intergroup heterogeneity [10]. Furthermore, many staging systems are rarely used in clinical practice because they are complex and cumbersome. Consequently, there is an urgent need to develop a reliable and convenient index for routine clinical practice.

Inflammation has been reported to be involved in the pathogenesis and progression of cancer, particularly in HCC patients with a background of chronic inflammation [11, 12]. A variety of inflammation response indices, including C-reactive protein (CRP) [13], fibrinogen [14], neutrophil to lymphocyte ratio (NLR) [15,16], Glasgow Prognostic Score (GPS) [17], Inflammation based score (IBS) [18] and Inflammation based index (IBI) [19], have been reported to represent useful prognostic markers for certain types of cancers, including HCC. Recently, FC scores, which incorporate preoperative plasma fibrinogen and CRP levels, were suggested to represent a prognostic marker in patients with esophageal squamous cell carcinoma [20]. However, there is a distinct lack of reports relating to FC scores for patients with HCC. In the present study, we aimed to investigate the prognostic predictive value of $\mathrm{FC}$ scores in patients with HCC, and compared the prognostic ability between FC scores and commonly-used evaluation systems.

\section{Materials and Methods}

\section{Patients}

This study involved 768 consecutive patients, who were diagnosed and underwent curative resection in Zhongshan Hospital of Fudan University between December 2010 and June 2012. Patients were randomly divided into two independent cohorts at a ratio of 4:1, including a training cohort (616 patients) and a validating cohort (152 patients). The inclusion and exclusion criteria in the study were as follows: (1) no history of preoperative anticancer therapy, (2) exact pathological diagnosis of HCC, (3) radical resection of the tumor without residual cancer with the cut surface being free of cancer by histological examination were defined as radical excision, (4) with complete clinicopathological characteristics and follow-up data, (5) without any evidence of extrahepatic metastasis or other organs with primary cancer. The study's protocol was approved by the Clinical Research Ethic Committee of Zhongshan Hospital and all parents provided informed consent.

\section{Laboratory Measurements}

Preoperative serum sample were collected in tubes without the influence of any treatment. Fibrinogen level was measured by a clotting assay (Dade Thrombin Reagent, Siemens Healthcare Diagnostic Products GmbH, Germany) and carried out on an Automated Blood Coagulation Analyzer (CA-700 Sysmex Cooperation Japan) according to the manufacturer's instruction. And the normal reference range was defined as being between 200 and 400 $\mathrm{mg} / \mathrm{dl}$. C-reactive protein (CRP) was detected by a Vitros 5.1 FS automatic biochemical analyzer (Johnson \& Johnson, New Brunswick, NJ, USA). And the normal reference scope for CRP range from 0.8 to 8 $\mathrm{mg} / \mathrm{L}$.

\section{Follow-up}

The exact follow-up procedure was described in our previous study [21]. Computed tomography (CT) as well as magnetic resonance imaging (MRI) were applied for further examination whenever there was a sign of intrahepatic recurrence or distal metastasis. The recurrence free survival (RFS) and overall survival (OS) times were calculated from surgery to the date of the first recurrence and death, respectively. For patients without any sign of an RFS/OS event, the final follow-up data were recorded as their terminal record.

\section{Statistical Analysis}

Statistical analysis was performed using SPSS version 21, and the Mann-Whitney $U$ test was used to compare two independent groups. Associations between variables were analyzed using the Pearson's chi-squared test. Survival curves were developed using the Kaplan-Meier method and comparisons carried out using the log-rank test. Univariate and multivariate analyses for independent prognostic factors were carried out using the Cox proportional hazard model. The optimal cut-off values for 
fibrinogen were determined using X-tile version 3.6.1 (Yale University, New Haven, CT, USA). A nomogram was then formulated based on the results from the multivariate analysis, and a C-index and calibration curve were generated to evaluate the discriminatory ability of each scoring system. Both the nomogram and the $\mathrm{C}$-index were completed with $\mathrm{R}$ version 3.0.2.

\section{Results}

\section{Patient Demographics}

This study involved a final cohort of 768 patients. Of these, 616 patients were classified into the training group, while 152 patients were classified into the validation group. The detailed demographics of both cohorts are shown in Table 1 and Table 2 . There were no significant differences between the two cohorts in terms of clinical characteristics except for ALB and IBI. By the final follow up date, on the $20^{\text {th }}$ December 2016, 115 patients had died. The median follow-up time was 48 months (range, 2-66 months), and the 1-, 3-, and 5-year OS were $95.3 \%, 78.8 \%$, and $67.4 \%$, respectively. The 1-, 2-, and 3-year FRS were $83.7,56.6 \%$, and $41.9 \%$, respectively.

\section{FC-scores, and the relationship between FC-score and Clinical Characteristics}

The optimal cutoff value for fibrinogen was 266 $\mathrm{mg} / \mathrm{dL}$, and was determined by X-tile. Thus, patients with both low fibrinogen $(<266 \mathrm{mg} / \mathrm{dL})$ and CRP $(<10$ $\mathrm{mg} / \mathrm{L}$ ) were allocated a score of 0 . Patients exhibiting only one of these abnormalities were given a score of 1, whilst those with both abnormal CRP and fibrinogen were given a score of 2 . Further analysis showed that serum AFP $(p=0.029)$, TBI $(p=0.05)$, GGT $(\mathrm{p}<0.001)$, ALB $(\mathrm{P}=0.001)$, PLT $(\mathrm{p}<0.001)$, along with the presence of hepatic cirrhosis $(p<0.001)$, tumor thrombus $(p<0.001)$ and MVI $(p<0.001)$, were found to be significantly positively associated with a high FC-score. Moreover, a high FC-score was significantly associated with advanced BCLC staging system $(\mathrm{P}<0.001)$, CLIP scores $(\mathrm{p}<0.001)$ and high levels of IBI, IBS, GPS (Table 2).

\section{Prognostic and Recurrence Factors for Patients with HCC in the training cohort}

Univariate analysis showed that FC-score was a significant prognostic indicator (Fig. 1 A, B and Supplementary table S1). Multivariate analysis further showed that FC-score $(H R=2.21, p<0.001)$, elevated preoperative serum AFP $(\mathrm{HR}=1.690$, $\mathrm{p}=0.008)$ IBS $(\mathrm{HR}=2.01, \quad \mathrm{p}<0.001)$ and cancer-associated characteristics including multiple tumors $(\mathrm{HR}=1.76, \mathrm{p}=0.004)$, the presence of tumor thrombus $(\mathrm{HR}=2.262, \mathrm{p}<0.001)$ and microvascular invasion $(\mathrm{HR}=1.93, \mathrm{p}=0.003)$, the $\mathrm{BCLC}$ staging system $(\mathrm{HR}=2.23, \mathrm{p}<0.001)$, and CLIP $(\mathrm{HR}=2.720$, $\mathrm{p}<0.001)$ were all significant independent prognostic factors for OS. Meanwhile, FC-score $(\mathrm{HR}=1.36$, $\mathrm{p}<0.001)$, IBS $(\mathrm{HR}=1.59, \mathrm{p}<0.001)$, multiple tumors ( $\mathrm{HR}=1.49, \mathrm{p}=0.012)$, the presence of tumor thrombus $(\mathrm{HR}=2.089, \mathrm{p}<0.001)$ and MVI $(\mathrm{HR}=1.388, \mathrm{p}=0.022)$, the BCLC staging system $(\mathrm{HR}=1.713, \mathrm{p}=0.003)$, and CLIP (HR=1.460, $\mathrm{p}=0.04$ ) were found to be poor indicators of RFS (Table 3).

In further subgroup analysis, FC-score was proven to represent a prominent prognostic factor for both OS and RFS $(p<0.05)$ (Fig. $1 \mathrm{E}-\mathrm{H})$.

Table 1. Demographic and clinical characteristics of patients

\begin{tabular}{|c|c|c|c|}
\hline & training cohort & validation cohort & \\
\hline Characters & $\mathrm{n}=616$ & $\mathrm{n}=152$ & P-value \\
\hline Gender, male/femeal & $514 / 102$ & $131 / 21$ & 0.409 \\
\hline Age, $<60 / \geq 60$ & $343 / 273$ & $80 / 72$ & 0.498 \\
\hline HBsAg, & & & \\
\hline $\begin{array}{l}\text { negative/positive } \\
\text { AFP }\end{array}$ & $100 / 516$ & $27 / 125$ & 0.649 \\
\hline $\begin{array}{l}<400 / \geq 400 \mathrm{ng} / \mathrm{mL} \\
\text { TBIL }\end{array}$ & $435 / 181$ & $113 / 39$ & 0.363 \\
\hline$<20 / \geq 20 \mu \mathrm{mol} / \mathrm{L}$ & $558 / 58$ & $136 / 16$ & 0.678 \\
\hline GGT, $<45 / \geq 45 \mathrm{U} / \mathrm{L}$ & $248 / 368$ & $63 / 89$ & 0.789 \\
\hline $\mathrm{ALT},<50 / \geq 50 \mathrm{U} / \mathrm{L}$ & $495 / 121$ & $119 / 33$ & 0.569 \\
\hline $\mathrm{ALB},<35 / \geq 35 \mathrm{~g} / \mathrm{L}$ & $21 / 595$ & $45 / 107$ & $<0.001$ \\
\hline $\mathrm{CRP},<10 / \geq 10 \mathrm{mg} / \mathrm{L}$ & $549 / 67$ & $136 / 16$ & 0.901 \\
\hline $\begin{array}{l}\mathrm{FIB},<266 / \geq 266 \mathrm{mg} / \mathrm{L} \\
\mathrm{PLT}\end{array}$ & $399 / 217$ & $102 / 50$ & 0.589 \\
\hline$<200 / \geq 20010^{\wedge} 9 / \mathrm{L}$ & $509 / 107$ & $124 / 28$ & 0.76 \\
\hline $\begin{array}{l}\text { cirrhosis,no/yes } \\
\text { tumor number, }\end{array}$ & $156 / 460$ & $37 / 115$ & 0.802 \\
\hline $\begin{array}{l}\text { single/multiple } \\
\text { tumor throbus }\end{array}$ & $533 / 83$ & $127 / 25$ & 0.345 \\
\hline $\begin{array}{l}\text { no/yes } \\
\text { tumor capsule }\end{array}$ & $577 / 39$ & $143 / 9$ & 0.852 \\
\hline $\begin{array}{l}\text { no/yes } \\
\text { tumor size }\end{array}$ & $394 / 222$ & $103 / 49$ & 0.38 \\
\hline$<5 / \geq 5 \mathrm{~cm}$ & $360 / 256$ & $78 / 74$ & 0.112 \\
\hline LNM & & & \\
\hline no/yes & $612 / 4$ & $150 / 2$ & 0.403 \\
\hline $\begin{array}{l}\text { MVI, no/yes } \\
\text { differentiation, }\end{array}$ & $450 / 166$ & $102 / 50$ & 0.144 \\
\hline I-II/III-IV & $421 / 195$ & $102 / 48$ & 0.985 \\
\hline IBS, $0 / 1$ & $12 / 551 / 52$ & $39 / 103 / 10$ & $<0.001$ \\
\hline GPS, $0 / 1 / 2$ & $535 / 73 / 8$ & $132 / 20 / 0$ & 0.342 \\
\hline IBI, $0 / 1 / 2$ & $322 / 294$ & $80 / 70$ & 0.711 \\
\hline FC-score, $0 / 1 / 2$ & $386 / 176 / 54$ & $97 / 44 / 11$ & 0.832 \\
\hline $\mathrm{BCLC}, \mathrm{A} / \mathrm{B} / \mathrm{C}$ & $401 / 186 / 29$ & $91 / 52 / 9$ & 0.468 \\
\hline CLIP, 0/1-3/4-6 & $337 / 272 / 7$ & $87 / 61 / 4$ & 0.287 \\
\hline
\end{tabular}

APF, alpha fetal protein; FIB, fibrinogen; PLT, platelet; LNM, lymph node metastasis; MVI, microvascular invasion; IBS, Inflammation based score; GPS, Glasgow Prognostic Score; IBI, inflammation based index; FC-score, fibrinogen and C-reactive protein score; BCLC, Barcelona Clinic Liver Cancer staging system; CLIP, Cancer Liver Italian Program.

\section{Comparison of Predictive accuracy between FC-score and other Predictive Models}

The C-index of the FC-score for OS and RFS (0.698 and 0.594, respectively) accounted for the third, only second to CLIP (0.724 and 0.622 , respectively) 
and BCLC (0.721 and 0.629, respectively), and was superior to that of other inflammation-based prognostic scores, including IBI (0.612 and 0.539, respectively), IBS (0.675 and 0.576, respectively), and GPS (0.629 and 0.542, respectively) (Table 4$)$.

\section{Validation of Prognostic Analysis in the validation cohort}

In the validation cohort, univariate analysis showed that the FC-score was a significant prognostic indicator (Fig. $1 \mathrm{C}, \mathrm{D}$ and Supplementary table S1). Additionally, FC-score (HR=2.862 for OS; $\mathrm{HR}=1.865$ for RFS) was an independent prognostic indicator for both OS and RFS in the multivariate analysis, which was consistent with results for the training cohort (Table 3). Furthermore, C-index of the FC-score system improved to a new state of 0.701 and 0.624 for OS and RFS, respectively (Table 4).

\section{A New Nomogram for Survival Prediction that integrates FC-score into the Routine Clinical Staging System}

We developed a novel nomogram that integrated the FC-score into the BCLC staging system for both OS and RFS (Fig. 2 A,B). The calibration curves, which represent an internal validation system, for the nomogram are shown in Fig. 2 C-F. The calibration plots show high concordance between prediction and actual observations for 3-year, 5-year OS and 1-year, 3-year RFS.

The novel nomogram showed better predictive accuracy (C-index, 0.746 and 0.654 for OS and RFS, respectively) than the BCLC staging system (C-index, 0.721 and 0.629 for OS and RFS, respectively) and the FC-score alone (C-index, 0.698 and 0.594 for OS and RFS, respectively) (Table 4).
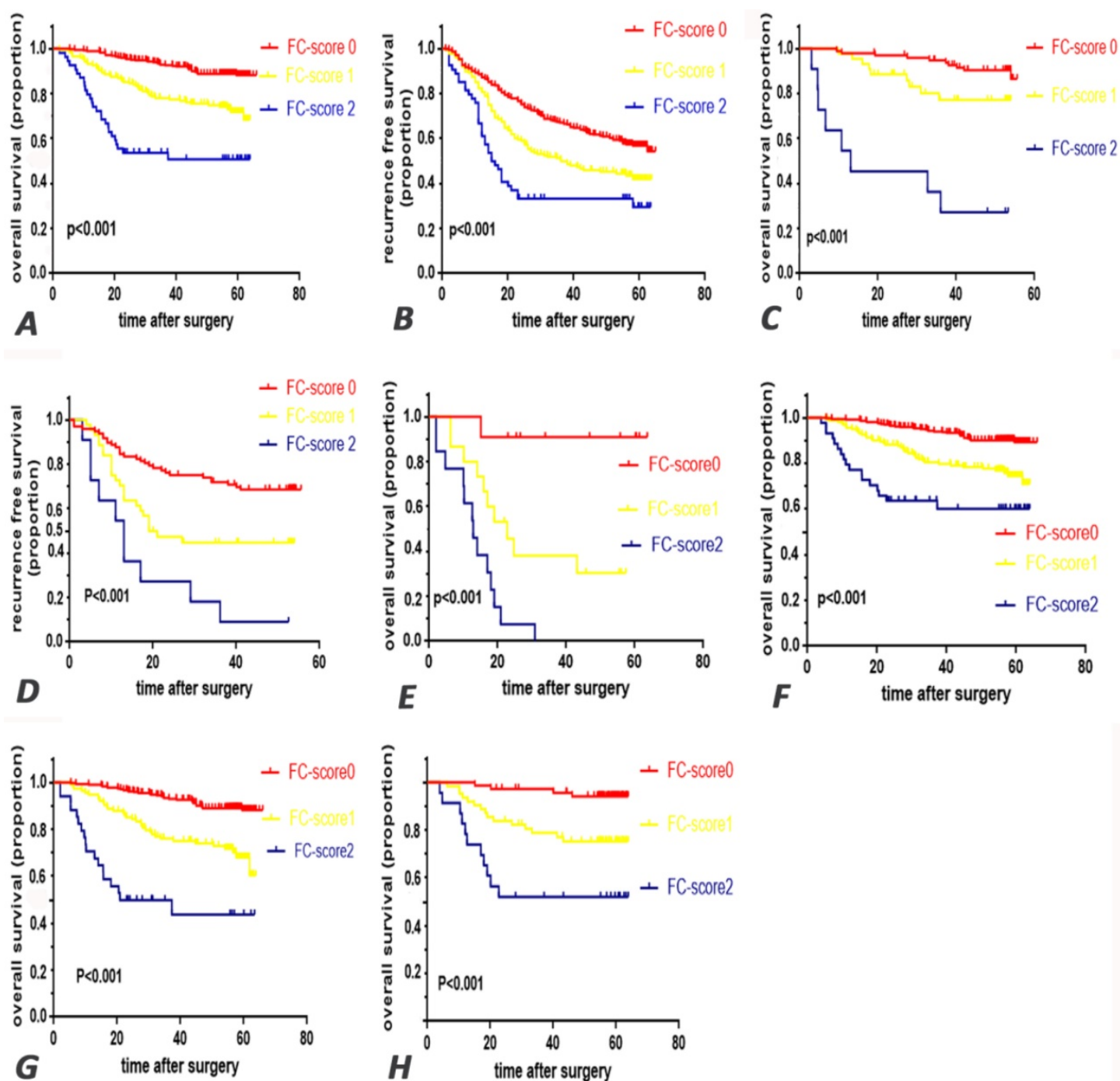

Figure 1. Kaplan-Meier survival curves for patients in the research by FC-score. overall survival (AC) and recurrence free survival (BD) in training cohort and validation cohort respectively. Furthermore, in the subgroup analysis for OS, E survival curve for patients in the subgroup with tumor thrombus, $F$ survival curve for patients without tumor thrombus. G survival curve for patients in the subgroup with hepatic cirrhosis, $\mathrm{H}$ for patients without hepatic cirrhosis. FC-score=fibrinogen and C-reactive protein score. 
Table 2. The correlation between clinicopathologic characters and FIB and FC-score (training cohort)



\section{Validations of the Prediction Ability of the Nomogram for Survival}

In the validation cohort, the C-indexes of the novel nomogram for OS and RFS were 0.779 and 0.669 , respectively, which were superior to that of the BCLC system alone (0.729 and 0.634, individually) and FC-score (0.701 and 0.624, individually) (Table 4). Furthermore, the calibration curve of the well-constructed nomogram fitted well in terms of prediction and observation (Supplementary Fig. S1 A-D).

\section{Comparison of the Nomogram and BCLC Stages by Decision Curve Analysis}

The decision curve analysis represents a novel method to evaluate the net clinical benefit of predictive models [22]. Our nomogram showed better net benefits with a wider range of threshold probability than either the BCLC or FC-score alone in terms of both OS and RFS by decision curve analysis in the training cohort (Fig. 2 G-I). Also, it fitted well at 2-year, 3-year OS and 2-year RFS in the validation cohort (Supplementary Fig.S1 E-G).

\section{Discussion}

In this study, we have developed a novel, effective and convenient predictive FC-score system, based on the levels of fibrinogen and CRP. Additionally, we created a new nomogram, incorporating the FC-score system into the BCLC staging system, which exhibited higher discrimination ability and was evaluated by calibration curve and decision curve analysis in two independent cohorts.

Multiple researches have focused on the prominent roles of fibrinogen and CRP in the prognostic prediction [23-28].However, in the researches by Zhang $X$ et al and Xiao-Hui Li et al, the value of serum fibrinogen was only researched in the training cohort thus absenting the validation study[23, 24]. The main advantages of the current study were that a relatively large HCC population who underwent curative resection was involved, and the findings in the training cohort were further verified in the validation cohort. Furthermore, nomograms which could give an individualized risk assessment for each patient were constructed, and the reliable evaluation index (C-index) was applied to assess the discrimination ability among the routine clinical prediction indexes. Not only calibration curve but also decision curve analysis was used to evaluated the prediction accuracy and clinical net benefit of our nomogram in the two independent cohorts, which could enhance the reliability and value of our research. Furthermore, the combination of CRP and fibrinogen was found to be more powerful prediction index than CRP and fibrinogen individually.

To the best of our knowledge, inflammation has been reported to be a key factor in the pathogenesis of tumors, and plays a prominent role in the development and metastasis of cancer, particularly in HCC, which would develop from a heavy chronic liver inflammatory disease [2, 11, 12]. Fibrinogen, which is synthesized by hepatocytes, plays a key role in activating the coagulation cascade [29]. Furthermore, a mounting number of research studies have demonstrated the prominent role of fibrinogen in the regulation of the inflammatory response. Previously, fibrinogen was reported to represent a pro-inflammatory factor for stroke and vascular 
disease [30-32]. Via the interaction of a ligand-receptor mechanism involving a wide range of immune cells such as monocytes and microphages, fibrinogen also plays a key role in regulating reactions within the inflammation cascade [30, 33]. Furthermore, the prominent role of fibrinogen in predicting prognosis has been reported in a large number of cancers, including HCC, advanced esophageal squamous cell carcinoma, renal cell carcinoma, and esophageal squamous cell carcinoma [23, 24, 34-37]. CRP, which is another prominent system inflammation response factor, has been reported to be closely associated with prognosis in HCC, pancreatic cancer, renal cancer, gastric cancer, lung cancer and lymphoma [26-27, 38-41]. Also, there were a systematic review and meta-analysis shown that high level of CRP and CRP/albumin were associated with poor survival $[25,28]$. Therefore, it is reasonable to incorporate fibrinogen and CRP to establish the FC-score.

Previously, CRP and fibrinogen were used to predict the occurrence of cardiac-cerebral vascular disease $[42,43]$. While the FC-score was first reported to represent a significant predictor in patients with esophageal squamous cell carcinoma, our study represents a new contribution to HCC research [20]. In our present research, FC-score was shown to be an independent prognostic variate. Patients with a high score on the FC-scoring system appear to be more likely to suffer from a poor prognosis and a high rate of recurrence. Besides, we also investigated the predictive ability of FC-scoring, and found that its efficiency and accuracy were superior to other routinely-used inflammatory based systems such as IBI, IBS, and GPS in terms of C-index. To investigate the common applicability of this scoring system across different groups of patients, we also conducted subgroup analysis and found that FC-score was indicated as a predictive factor for patients classified by hepatic cirrhosis and tumor thrombus. In the correlation analysis, FC-score was effective in relation to a wide variety of factors: tumor capsule; differentiation; tumor thrombus; AFP level; tumor number; and tumor size. Consequently, FC-score can be widely used as a predictor across many different subgroups of patients.

Table 3. Multivariate analyses for OS and RFS in HCC patients.

\begin{tabular}{|c|c|c|c|c|c|c|c|c|}
\hline \multirow[b]{3}{*}{ characters } & \multicolumn{4}{|c|}{ training cohort } & \multicolumn{4}{|c|}{ validation cohort } \\
\hline & OS & & RFS & & OS & & RFS & \\
\hline & $\begin{array}{l}\text { multivariate } \\
\text { P-value }\end{array}$ & $\begin{array}{l}\text { HR } \\
(95 \% \mathrm{CI})\end{array}$ & $\begin{array}{l}\text { multivariate } \\
\text { P-value }\end{array}$ & $\begin{array}{l}\text { HR } \\
(95 \% \mathrm{CI})\end{array}$ & $\begin{array}{l}\text { multivariate } \\
\text { P-value }\end{array}$ & $\begin{array}{l}\text { HR } \\
(95 \% \mathrm{CI})\end{array}$ & $\begin{array}{l}\text { multivariate } \\
\text { P-value }\end{array}$ & $\begin{array}{l}\text { HR } \\
(95 \% \mathrm{CI})\end{array}$ \\
\hline $\mathrm{AFP},<400 / \geq 400 \mathrm{ng} / \mathrm{mL}$ & & & & & 0.008 & $1.690(1.14-2.49)$ & & \\
\hline single/multiple & & & & & 0.004 & $1.768(1.11-2.82)$ & 0.012 & $1.49(1.09-2.05)$ \\
\hline tumor throbus, no/yes & 0.03 & 2.091(1.59-7.41) & 0.032 & $2.428(1.75-4.44)$ & $<0.001$ & $2.262(1.32-3.88)$ & $<0.001$ & $2.089(1.38-3.15)$ \\
\hline $\begin{array}{l}\text { Lymph node metastasis, } \\
\text { no/yes }\end{array}$ & 0.017 & $8.466(1.46-48.91)$ & & & & & & \\
\hline MVI, no/yes & 0.044 & $2.298(1.86-6.09)$ & 0.037 & $1.802(1.13-2.75)$ & 0.003 & $1.93(1.26-2.96)$ & 0.022 & $1.388(1.05-1.84)$ \\
\hline $\begin{array}{l}\text { IBS, } 0 / 1 \\
\text { GPS, } 0 / 1 / 2\end{array}$ & 0.01 & $3.036(2.92-6.96)$ & 0.015 & $1.912(1.14-3.22)$ & 0.001 & $2.01(1.32-3.03)$ & $<0.001$ & $1.59(1.25-2.02)$ \\
\hline IBI, $0 / 1 / 2$ & 0.05 & $2.989(0.98-9.09)$ & 0.036 & $2.054(1.05-4.03)$ & & & & \\
\hline FC-score, $0 / 1 / 2$ & 0.008 & $2.862(1.31-6.26)$ & 0.023 & $1.865(1.09-3.19)$ & $<0.001$ & $2.21(1.48-3.26)$ & 0.012 & $1.36(1.07-1.73)$ \\
\hline $\mathrm{BCLC}, \mathrm{A} / \mathrm{B} / \mathrm{C}$ & 0.024 & $2.173(1.11-4.26)$ & 0.016 & 1.712(1.11-2.65) & $<0.001$ & $2.23(1.63-3.06)$ & 0.003 & $1.713(1.19-2.45)$ \\
\hline CLIP, 0/1-3/4-6 & $<0.001$ & 7.956(3.41-18.58) & 0.004 & $1.967(1.24-3.11)$ & $<0.001$ & $2.72(1.76-4.21)$ & 0.04 & $1.46(1.02-2.09)$ \\
\hline
\end{tabular}

Table 4. Ranking of clinical staging system using C-index for OS and RFS

\begin{tabular}{|c|c|c|c|c|c|c|c|c|}
\hline \multirow{3}{*}{ Variables } & \multicolumn{4}{|c|}{ Training cohort } & \multicolumn{4}{|c|}{ Validation cohort } \\
\hline & \multicolumn{2}{|l|}{ OS } & \multicolumn{2}{|l|}{ RFS } & \multicolumn{2}{|l|}{ OS } & \multicolumn{2}{|l|}{ RFS } \\
\hline & c-index & $95 \% \mathrm{CI}$ & c-index & $95 \% \mathrm{CI}$ & c-index & $95 \% \mathrm{CI}$ & c-index & $95 \% \mathrm{CI}$ \\
\hline nomogram & 0.746 & $0.743-0.749$ & 0.654 & $0.652-0.656$ & 0.774 & $0.771-0.777$ & 0.669 & $0.666-0.672$ \\
\hline BCLC & 0.721 & $0.718-0.724$ & 0.629 & $0.627-0.631$ & 0.729 & $0.726-0.723$ & 0.634 & $0.631-0.631$ \\
\hline CLIP & 0.724 & $0.721-0.727$ & 0.622 & $0.620-0.624$ & 0.738 & $0.735-0.741$ & 0.631 & $0.628-0.634$ \\
\hline FC-score & 0.698 & $0.695-0.701$ & 0.594 & $0.592-0.596$ & 0.701 & $0.698-0.704$ & 0.624 & $0.621-0.627$ \\
\hline IBS & 0.675 & $0.672-0.678$ & 0.576 & $0.574-0.678$ & 0.709 & $0.706-0.712$ & 0.611 & $0.608-0.614$ \\
\hline GPS & 0.629 & $0.626-0.631$ & 0.542 & $0.540-0.544$ & 0.594 & $0.591-0.593$ & 0.532 & $0.529-0.535$ \\
\hline IBI & 0.612 & $0.609-0.615$ & 0.539 & $0.537-0.541$ & 0.657 & $0.654-0.660$ & 0.615 & $0.612-0.618$ \\
\hline $\mathrm{CRP},<10 / \geq 10 \mathrm{mg} / \mathrm{L}$ & 0.614 & $0.611-0.617$ & 0.553 & $0.551-0.555$ & 0.624 & $0.621-0.627$ & 0.566 & $0.563-0.569$ \\
\hline $\mathrm{FIB},<266 / \geq 266 \mathrm{mg} / \mathrm{dL}$ & 0.636 & $0.633-0.639$ & 0.556 & $0.554-0.558$ & 0.638 & $0.635-0.641$ & 0.604 & $0.601-0.607$ \\
\hline
\end{tabular}

IBS, Inflammation based score; GPS, Glasgow Prognostic Score; IBI, inflammation based index; FC-score, fibrinogen and C-reactive protein score; BCLC, Barcelona Clinic Liver Cancer staging system; CLIP, Cancer Liver Italian Program. 

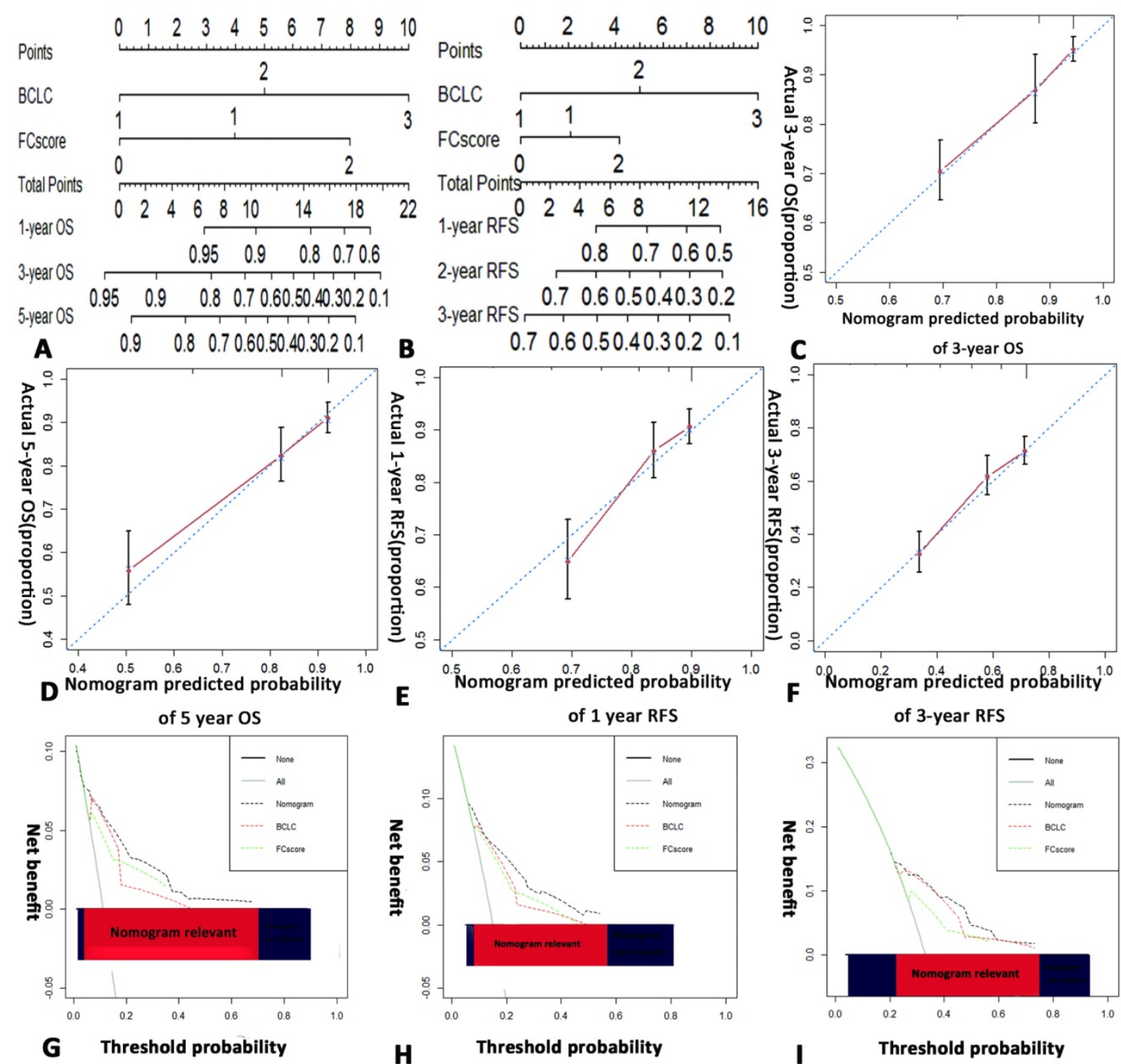

Figure 2. Hepatocellular carcinoma (HCC) OS and RFS nomogram, calibration curve, and decision curve analysis in the training cohort. (A for OS and B for RFS). To use the nomogram, the value of an individual patient is located on each variable axis, and a line is drawn upward to determine the number of points received for each variable value. the sum of these numbers is located on the total point axis, and a line is drawn downward to the survival axes to determine the likelihood of 1-,3-, and 5 -year survival. The calibration curve for predicting OS at (C) 3 years, (D) 5 years, and predicting RFS at (E) 1 year, (F) 3 years. Nomogram-predicted probability of overall survival is plotted on the $x$ axis and actual overall survival is plotted on the $y$ axis. Decision curve analyses depict the clinical net benefit in pairwise comparisons across the different models. Nomogram is compared with the BCLC stage in terms of (G) 2-year, (H) 3-year OS and (I) 2-year RFS. Dashed lines indicate the net benefit of nomogram in each of the curves across a range of threshold probabilities. The horizontal solid black line represents the assumptions that no patient will experience the event, and the solid grey line represents the assumption that all patients will relapse. On decision curve analysis, nomogram showed superior net benefit compared with BCLC stage across a range of threshold probabilities. $B C L C=$ Barcelona Clinic Liver cancer, OS=overall survival, RFS=recurrence free survival.

Routine clinical predictive systems, such as the BCLC and CLIP, unfortunately lack the involvement of an inflammatory index [6, 44, 45]. Also, these traditional systems lack flexibility for the heterogeneity of the tumor. The nomogram, which provides a more individualized prediction, is a statistical model based on a combination of variables. Until now, many nomograms have been established for a range of different types of cancer and have shown superior prediction [46-48]. Therefore, we developed new nomograms that integrated FC-score with BCLC for both OS and RFS, thus creating a much stronger predictor for individual patients.
Interestingly, improvements in the predictive ability for both OS and RFS were observed with FC-scores or the BCLC alone, which was validated in the validation group. Our present research, together with findings from our previous studies, supported the prominent role of inflammation in prognostic prediction [18]. Consequently, our findings suggest that the FC-scoring system, with its wide range of applications, is a very reliable and convenient predictive system.

Several limitations need to be considered in our present study. Firstly, this was a retrospective study in a single institution in China. Secondly, this study 
only focused on patients undergoing curative resection. Finally, whether our new nomogram can be applied to patients who receive treatment other than curative resection remains to be determined. Hence, it is important to carry out a multicenter study and enroll a large number of patients with advanced clinical stages and different therapy strategies in the future.

\section{Conclusions}

In conclusion, FC-score represents a novel, convenient, reliable, and accurate prognostic predictor for both OS and RFS in patients with HCC undergoing curative resection. The newly developed nomogram gives rise to better discrimination ability for individual prediction.

\section{Supplementary Material}

Table S1 and Figure S1.

http://www.jcancer.org/v09p0148s1.pdf

\section{Acknowledgements}

This work was supported by National Key Sci-Tech Special Project of China (Grant No. 2012ZX10002010-001/002); the National Natural Science Foundation of China (Grant Nos. 81302102); Research Programs of Science and Technology Commission Foundation of Shanghai (Grant No. 13CG04, 16DZ0500300).

\section{Competing Interests}

The authors have declared that no competing interest exists.

\section{References}

1. Dutta R, Mahato RI. Recent advances in hepatocellular carcinoma therapy. Pharmacology \&therapeutics. 2017;173:106-17.

2. Dawe RS. Hepatocellular carcinoma. Lancet. 2004;363:899.

3. Ferlay J, Soerjomataram I, Dikshit R, Eser S, Mathers C, Rebelo M, et al. Cancer incidence and mortality worldwide: sources, methods and major patterns in GLOBOCAN 2012. International journal of cancer. 2015;136:E359-86.

4. Gish RG, Porta C, Lazar L, Ruff P, Feld R, Croitoru A, et al. Phase III randomized controlled trial comparing the survival of patients with unresectable hepatocellular carcinoma treated with nolatrexed or doxorubicin. Journal of clinical oncology : official journal of the American Society of Clinical Oncology. 2007;25:3069-75

5. Tandon P, Garcia-Tsao G. Prognostic indicators in hepatocellular carcinoma: a systematic review of 72 studies. Liver international : official journal of the International Association for the Study of the Liver. 2009;29:502-10.

6. Cillo U, Vitale A, Grigoletto F, Farinati F, Brolese A, Zanus G, et al. Prospective validation of the Barcelona Clinic Liver Cancer staging system. Journal of hepatology. 2006;44:723-31.

7. Llovet JM, Di BAM, Bruix J, Kramer BS, Lencioni R, Zhu AX, et al. Design and endpoints of clinical trials in hepatocellular carcinoma. Journal of the National Cancer Institute. 2008;100:698-711.

8. Lin CY, Kee KM, Wang JH, Lee CM, Chen CL, Changchien CS, et al. Is the Cancer of the Liver Italian Program system an adequate weighting for survival of hepatocellular carcinoma? Evaluation of intrascore prognostic value among 36 subgroups. Liver international : official journal of the International Association for the Study of the Liver. 2009:29:74-81.

9. Cammà C, Di MV, Cabibbo G, Latteri F, Sandonato L, Parisi P, et al. Survival of patients with hepatocellular carcinoma in cirrhosis: a comparison of BCLC, CLIP and GRETCH staging systems. Alimentary pharmacology \& therapeutics. 2008;28:62-75.
10. Cammà C, Cabibbo G. Prognostic scores for hepatocellular carcinoma: none is the winner. Liver international : official journal of the International Association for the Study of the Liver. 2009;29:478-80.

11. Brennan CA, Garrett WS. Gut Microbiota, Inflammation, and Colorectal Cancer. Annual review of microbiology. 2016;70:395-411.

12. Cabillic F, Corlu A. Regulation of Transdifferentiation and Retrodifferentiation by Inflammatory Cytokines in Hepatocellular Carcinoma. Gastroenterology. 2016;151:607-15.

13. Polterauer S, Grimm C, Zeillinger R, Heinze G, Tempfer C, Reinthaller A, et al. Association of C-reactive protein (CRP) gene polymorphisms, serum CRP levels and cervical cancer prognosis. Anticancer research. 2011;31:2259-64.

14. Tang LQ, Chen QY, Guo SS, Chen WH, Li CF, Zhang L, et al. The impact of plasma Epstein-Barr virus DNA and fibrinogen on nasopharyngeal carcinoma prognosis: an observational study. British journal of cancer. 2014;111:1102-11.

15. Kang MH, Go SI, Song HN, Lee A, Kim SH, Kang JH, et al. The prognostic impact of the neutrophil-to-lymphocyte ratio in patients with small-cell lung cancer. British journal of cancer. 2014;111:452-60.

16. Templeton AJ, Pezaro C, Omlin A, McNamara MG, Leibowitz-Amit R, Vera-Badillo FE, et al. Simple prognostic score for metastatic castration-resistant prostate cancer with incorporation of neutrophil-to-lymphocyte ratio. Cancer. 2014;120:3346-52.

17. Forrest LM, McMillan DC, McArdle CS, Angerson WJ.Dunlop DJ. Evaluation of cumulative prognostic scores based on the systemic inflammatory response in patients with inoperable non-small-cell lung cancer. British journal of cancer. 2003;89:1028-30.

18. Fu YP, Ni XC, Yi Y, Cai XY, He HW, Wang JX, et al. A Novel and Validated Inflammation-Based Score (IBS) Predicts Survival in Patients With Hepatocellular Carcinoma Following Curative Surgical Resection: A STROBE-Compliant Article. Medicine. 2016;95:e2784

19. Pinato DJ, Stebbing J, Ishizuka M, Khan SA, Wasan HS, North BV, et al. A novel and validated prognostic index in hepatocellular carcinoma: the inflammation based index (IBI). Journal of hepatology. 2012;57:1013-20.

20. Tian R, Yan H, Zhang F, Sun P, Wu AR, Zhang M, et al. Cumulative score based on preoperative plasma fibrinogen and serum C-reactive protein could predict long-term survival for esophageal squamous cell carcinoma. Oncotarget. 2016;7:61533-43.

21. Sun HC, Zhang W, Qin LX, Zhang BH, Ye QH, Ren N, et al. Positive serum hepatitis $\mathrm{B}$ e antigen is associated with higher risk of early recurrence and poorer survival in patients after curative resection of hepatitis B-related hepatocellular carcinoma. Journal of Hepatology. 2007;47(5):684-90.

22. Fitzgerald $M$, Saville BR.Lewis RJ. Decision curve analysis. JAMA. 2015;313:409-10.

23. Zhang $X$, Long Q. Elevated serum plasma fibrinogen is associated with advanced tumor stage and poor survival in hepatocellular carcinoma patients. Medicine. 2017:96:e6694.

24. Li XH, Gu WS, Wang XP, Lin JH, Zheng X, Zhang L, et al. Low Preoperative albumin-to-globulin ratio Predict Poor Survival and Negatively Correlated with Fibrinogen in Resectable Esophageal Squamous Cell Carcinoma. Journal of Cancer. 2017;8:1833-42

25. Shrotriya S, Walsh D, Bennani-Baiti N, Thomas S.Lorton C. C-Reactive Protein Is an Important Biomarker for Prognosis Tumor Recurrence and Treatment Response in Adult Solid Tumors: A Systematic Review. PloS one. 2015;10:e0143080.

26. Li YJ, Li ZM, Xia Y, Huang JJ, Huang HQ, Xia ZJ, et al. Serum C-reactive protein (CRP) as a simple and independent prognostic factor in extranodal natural killer/T-cell lymphoma, nasal type. PloS one. 2013;8:e64158.

27. Tulek B, Koylu H, Kanat F, Arslan U.Ozer F. Serum C-reactive protein and procalcitonin levels in non-small cell lung cancer patients. Contemporary oncology Współczesna onkologia. 2013;17:68-72.

28. Xu HJ, Ma Y, Deng F, Ju WB, Sun XY.Wang H. The prognostic value of C-reactive protein/albumin ratio in human malignancies: an updated meta-analysis. OncoTargets and therapy. 2017;10:3059-70.

29. Tennent GA, Brennan SO, Stangou AJ, O'Grady J, Hawkins PN.Pepys MB. Human plasma fibrinogen is synthesized in the liver. Blood. 2007;109:1971-4.

30. Adams RA, Passino M, Sachs BD, Nuriel T.Akassoglou K. Fibrin mechanisms and functions in nervous system pathology. Molecular interventions. 2004;4:163-76

31. Date K, Ohyama M.Ogawa H. Carbohydrate-binding activities of coagulation factors fibrinogen and fibrin. Glycoconjugate journal. 2015;32:385-92.

32. Kattula S, Byrnes JR.Wolberg AS. Fibrinogen and Fibrin in Hemostasis and Thrombosis. Arteriosclerosis, thrombosis, and vascular biology. 2017:37:e13-13e21.

33. Solovjov DA, Pluskota E.Plow EF. Distinct roles for the alpha and beta subunits in the functions of integrin alphaMbeta2. The Journal of biological chemistry. 2005;280:1336-45.

34. Fu SJ, Ji F, Han M, Chen MG, Wang XP, Ju WQ, et al. Prognostic value of combined preoperative fibrinogen and neutrophil-lymphocyte ratio in patients with hepatocellular carcinoma after liver transplantation. Oncotarget. 2017;8:4301-12.

35. Kijima T, Arigami T, Uchikado Y, Uenosono Y, Kita Y, Owaki T, et al. Combined fibrinogen and neutrophil-lymphocyte ratio as a prognostic marker of advanced esophageal squamous cell carcinoma. Cancer science. 2017; 108(2):193-9.

36. Pichler M, Hutterer GC, Stojakovic T, Mannweiler S, Pummer K.Zigeuner R. High plasma fibrinogen level represents an independent negative prognostic 
factor regarding cancer-specific, metastasis-free, as well as overall survival in a European cohort of non-metastatic renal cell carcinoma patients. British journal of cancer. 2013. 109(5): 1123-9.

37. Zhang D, Zhou X, Bao W, Chen Y, Cheng L, Qiu G, et al. Plasma fibrinogen levels are correlated with postoperative distant metastasis and prognosis in esophageal squamous cell carcinoma. Oncotarget. 2015. 6(35): 38410-20.

38. Esfahani A, Makhdami N, Faramarzi E, Asghari JM, Ostadrahimi A, Ghayour NM, et al. Prealbumin/CRP Based Prognostic Score, a New Tool for Predicting Metastasis in Patients with Inoperable Gastric Cancer. Gastroenterology research and practice. 2016;2016:4686189.

39. Køstner AH, Kersten C, Löwenmark T, Ydsten KA, Peltonen R, Isoniemi H, et al. The prognostic role of systemic inflammation in patients undergoing resection of colorectal liver metastases: C-reactive protein (CRP) is a strong negative prognostic biomarker. Journal of surgical oncology. 2016;114:895-9.

40. Liu Z, Jin K, Guo M, Long J, Liu L, Liu C, et al. Prognostic Value of the $\mathrm{CRP} / \mathrm{Alb}$ Ratio, a Novel Inflammation-Based Score in Pancreatic Cancer. Annals of surgical oncology. 2017;24:561-8.

41. Xia WK, Wu X, Yu TH, Wu Y, Yao XJ.Hu H. Prognostic significance of lymphocyte-to-monocyte ratio and CRP in patients with nonmetastatic clear cell renal cell carcinoma: a retrospective multicenter analysis. OncoTargets and therapy. 2016;9:2759-67.

42. Kaptoge S, Di AE, Pennells L, Wood AM, White IR, Gao P, et al. C-reactive protein, fibrinogen, and cardiovascular disease prediction. The New England journal of medicine. 2012;367:1310-20.

43. Ammirati E, Maseri A. C-reactive protein, fibrinogen, and cardiovascular risk. The New England journal of medicine. 2013;368:85

44. Kudo M, Chung H, Haji S, Osaki Y, Oka H, Seki T, et al. Validation of a new prognostic staging system for hepatocellular carcinoma: the JIS score compared with the CLIP score. Hepatology : official journal of the American Association for the Study of Liver Diseases. 2004;40:1396-405.

45. Llovet JM, Brú C.Bruix J. Prognosis of hepatocellular carcinoma: the BCLC staging classification. Seminars in liver disease. 1999;19:329-38.

46. Xu L, Peng ZW, Chen MS, Shi M, Zhang YJ, Guo RP, et al. Prognostic nomogram for patients with unresectable hepatocellular carcinoma after transcatheter arterial chemoembolization. Journal of hepatology. 2015;63:122-30.

47. Brockman JA, Alanee S, Vickers AJ, Scardino PT, Wood DP, Kibel AS, et al. Nomogram Predicting Prostate Cancer-specific Mortality for Men with Biochemical Recurrence After Radical Prostatectomy. European urology. 2015;67:1160-7.

48. Young KA, Efiong E, Dove JT, Blansfield JA, Hunsinger MA, Wild JL, et al. External Validation of a Survival Nomogram for Non-Small Cell Lung Cancer Using the National Cancer Database. Annals of surgical oncology. 2017;24:1459-64. 